Provided for non-commercial research and education use. Not for reproduction, distribution or commercial use.

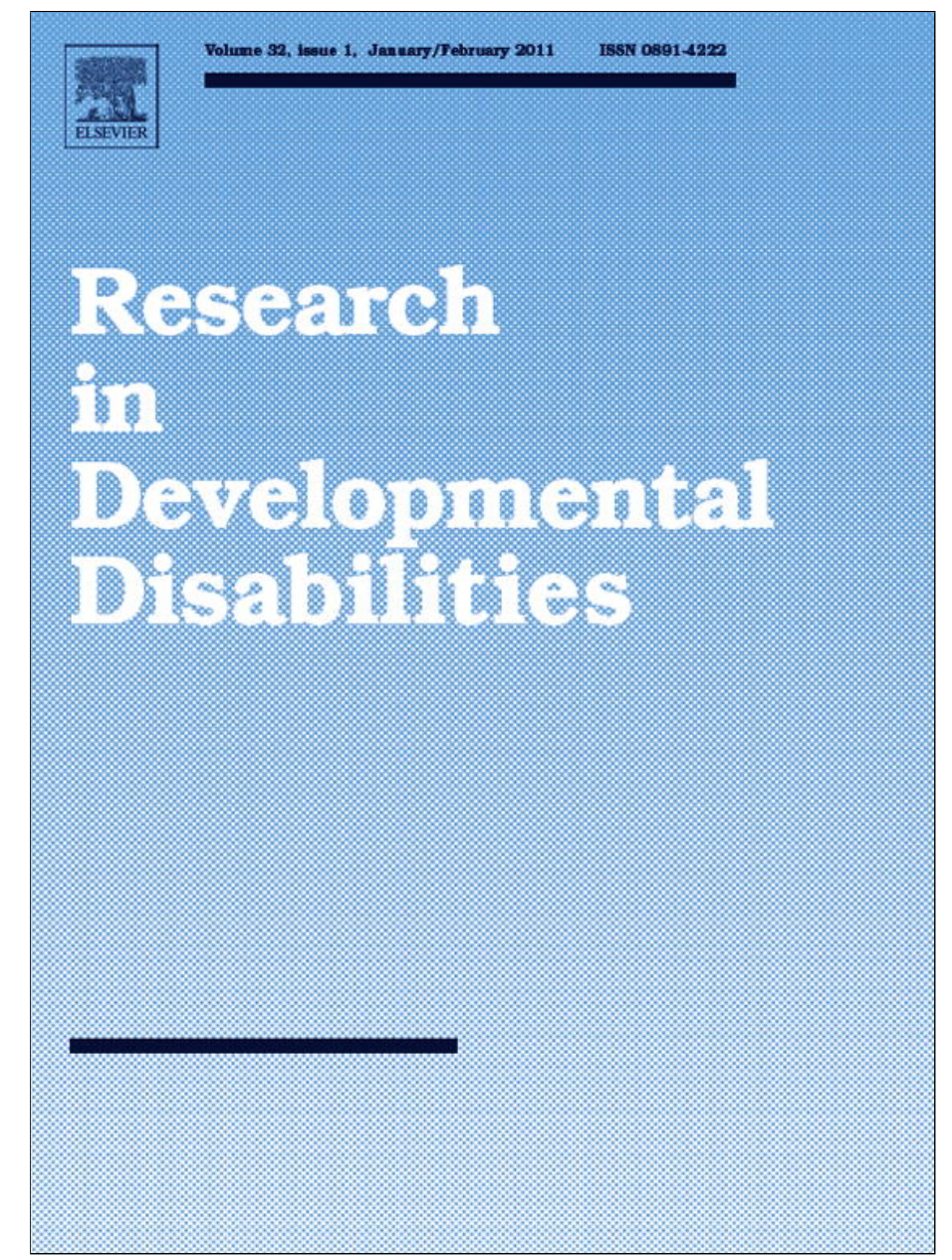

(This is a sample cover image for this issue. The actual cover is not yet available at this time.)

This article appeared in a journal published by Elsevier. The attached copy is furnished to the author for internal non-commercial research and education use, including for instruction at the authors institution and sharing with colleagues.

Other uses, including reproduction and distribution, or selling or licensing copies, or posting to personal, institutional or third party websites are prohibited.

In most cases authors are permitted to post their version of the article (e.g. in Word or Tex form) to their personal website or institutional repository. Authors requiring further information regarding Elsevier's archiving and manuscript policies are encouraged to visit:

http://www.elsevier.com/copyright 


\title{
Psycholinguistic abilities of children with Williams syndrome
}

\author{
Natalia F. Rossi ${ }^{a, 1, *}$, Elena Garayzábal Heinze ${ }^{\text {b,1,**}}$, Célia M. Giacheti a , \\ Óscar F. Gonçalves ${ }^{c}$, Adriana Sampaio ${ }^{c}$ \\ ${ }^{a}$ Department of Speech-Language Pathology, Philosophy and Sciences Faculty, University Estadual Paulista (UNESP), Marília, São Paulo, Brazil \\ ${ }^{\mathrm{b}}$ Department of Linguistics, University Autónoma of Madrid, 28049 Madrid, Spain \\ ${ }^{\mathrm{c}}$ Neuropsychophysiology Lab, CIPsi, School of Psychology, University of Minho, Braga, Portugal
}

\section{A R T I C L E I N F O}

\section{Article history:}

Received 4 November 2011

Received in revised form 21 November 2011

Accepted 15 December 2011

Available online

\section{Keywords:}

Williams syndrome

Psycholinguistic abilities

Visual and auditory processing

\begin{abstract}
A B S T R A C T
The objective of this study was to investigate the psycholinguistic abilities of children with Williams syndrome (WS) and typically developing children using the Illinois Test of Psycholinguistic Abilities (ITPA). Performance on the ITPA was analysed in a group with WS $(N=20$, mean age $=8.5$ years, $S D=1.62)$ and two typically developing groups, matched in mental (MA, $N=20$, mean age $=4.92$ years, $\mathrm{SD}=1.14)$ and chronological age $(\mathrm{CA}, N=19$, mean age $=8.35$ years, $S D=3.07)$. Overall, within-group analyses showed that individuals with WS displayed higher scalar scores on the visual reception and visual association subtests. When groups were compared, we observed inferior performance of the WS group on all ITPA subtests when compared with typically developing groups. Moreover, an interaction between reception and group was found, only the WS group demonstrated superior performance on the visual reception subtest when compared to the auditory reception subtest. Evidence from this study offers relevant contributions to the development of educational intervention programs for children with WS.
\end{abstract}

() 2011 Elsevier Ltd. All rights reserved.

\section{Introduction}

Williams syndrome (WS) is a neurodevelopmental disorder characterised by a $1.5 \mathrm{Mb}$ microdeletion on chromosome 7q11.23 that includes approximately 28 genes (Schubert, 2009). This genetic condition exhibits a cognitive profile characterised by a pattern of peaks and valleys in terms of cognitive abilities (Bellugi, Lichtenberger, Jones, Lai, \& St. George, 2000). Specifically, the initial reports of WS document intellectual disability and profound impairment in visuospatial processing coupled with relatively good language abilities. Interestingly, much of the research interest in WS was fostered by this apparent dissociative pattern of neurodevelopment (Bellugi, Bihrle, Jernigan, Trauner, \& Doherty, 1990), although these initial reports of excellent performance in language have been questioned (Brock, 2007; Cherniske et al., 2004; Gonçalves et al., 2004; Greer, Brown, Pai, Choudry, \& Klein, 1997; Karmiloff-Smith, Brown, Grice, \& Paterson, 2003; Porter \& Coltheart, 2005; Sampaio et al., 2009; Stojanovik, Perkins, \& Howard, 2006).

Intellectual disability is another feature of WS. Several studies use different measures of global intelligence to point out a high prevalence of intellectual disability; scores of children with WS generally fall in the interval Full Scale IQ ranging from 55 to 70 (Martens, Wilson, \& Reutens, 2008, for a general review). This global intellectual functioning is associated with a

\footnotetext{
* Corresponding author at: Philosophy and Sciences Faculty, University Estadual Paulista (UNESP), Avenida Hygino Muzzi Filho, 737, CEP: 17525-900 Marília, São Paulo, Brazil.

** Corresponding author.

E-mail addresses: nataliafreitasrossi@yahoo.com.br (N.F. Rossi), elena.garayzabal@uam.es (E. Garayzábal Heinze).

${ }^{1}$ Share equal first authorship.
} 
heterogeneous profile (Porter \& Coltheart, 2005), and a Williams Syndrome Cognitive Profile (Mervis et al., 2000; Pani, Mervis, \& Robinson, 1999) that takes performance on specific subtests into account has been proposed.

While both overall cognitive measures and specific tests to assess verbal and nonverbal developmental trajectories have been used extensively in characterising the WS cognitive profile (Jarrold, Baddeley, \& Hewes, 1998; Jarrold, Hartley, Phillips, \& Baddeley, 2000), few studies have provided a detailed characterisation of psycholinguistic abilities that takes both visual and auditory information processing skills into account.

Performance on the Illinois Test of Psycholinguistic Abilities (ITPA) (Kirk \& McCarthy, 1961) has provided inconsistent information about the relative impairment of visual and auditory processing in children with WS (Crisco, Dobbs, \& Mulhern, 1988; Gejão et al., 2007; Nakamura et al., 1999). According to Crisco et al., visual processing abilities as measured by the ITPA were significantly different in children with WS when compared with those of a control group. Specifically, individuals with WS demonstrated more difficulty performing visual reception, visual closure and visual memory tasks; visual processing abilities were generally below their cognitive level. However, Nakamura et al. (1999) described a single WS case in which scores for both the auditory and visual processing subtests were equally below normal. Finally, a Brazilian case report in which the ITPA was used to monitor language acquisition in children with WS showed that visual performance on ITPA subtests was within the normal range while cognitive difficulties were more prominent in auditory subtests (Gejão et al., 2007).

Taking into account both the inconsistent findings regarding auditory and visual information processing and the limited number of studies using the ITPA to assess cognitive abilities in children with WS, the main objective of this study was to compare psycholinguistic abilities measured using the ITPA of a group of individuals with WS (with confirmed fluorescence in situ hybridization - FISH) with those of two typically developing groups (a chronological age-matched group and a mental age-matched group).

\section{Materials and methods}

\subsection{Participants}

The Ethical Board (no. 256/2006) approved the current study. Written informed consent was obtained from all participating individuals and/or their parents prior to enrolment. The WS group included 20 individuals with confirmed genetic diagnoses (Ewart et al., 1993), with a mean age of 8.5 years (SD $=1.62$ years, participant ages ranged from 5.5 years to 10.75 years) and a mean Full Scale IQ of $56.72(S D=10.08$, range $42-75)$. Individuals with WS were recruited from the Brazilian Williams Syndrome Association (ABSW, $N=12$ ) and from the Spanish Williams Syndrome Association (ASWE, $N=8$ ). Typically developing groups consisted of a chronological age-matched group (CA, $N=19)$, with a mean age of 8.35 years $(S D=1.75 ; \mathrm{FSIQ}=96.58, \mathrm{SD}=2.22)$, and a mental age-matched group (MA, $N=20)$, with a mean age of 4.92 years $(S D=1.14 ;$ FSIQ $=97.05, S D=3.07)$. Spanish and Brazilian participants in the CA and MA groups were typically developing individuals with no evidence of speech-language disorders, learning disabilities, hearing loss, or visual impairment. Mental age for the MA group was derived for each participant according to Full Scale IQ (Terman, 1916). Finally, all participants had normal hearing assessed through behavioural audiometry and/or threshold tonal audiometry as well as normal or corrected-to-normal vision. Two participants with auditory thresholds below $25 \mathrm{dBNSat}$ several frequencies were excluded from this study (Davis \& Silverman, 1970). Demographic characteristics of the groups are shown in Table 1.

\subsection{Instruments}

To assess the general cognitive functioning level (Full Scale IQ - FSIQ), the Wechsler Preschool and Primary Scale of Intelligence-R (WPPSI-R) and Wechsler Intelligence Scale for Children-Third Edition (WISC-III) were used for children between 3-6 years of age and 6-11 years of age, respectively (Wechsler, 1989, 1991).

The Brazilian (Bogossian \& Santos, 1977) and Spanish versions (Kirk, McCarthy, \& Kirk, 1986) of the Illinois Test of Psycholinguistic Abilities (ITPA) (Kirk \& McCarthy, 1961) were used in the present study. This test assesses psycholinguistic abilities that are important for communication, namely those related to the ability to understand, process, and relate visually and aurally presented stimuli. The ITPA model was developed using a language-learning model proposed by Kirk that consists of two primary input channels for communication (auditory and visual), two primary output channels (verbal and motor), three psycholinguistic processes (reception, association and expression) and two organisation levels (automatic and

Table 1

Demographic characteristics of the ws and typically developing groups.

\begin{tabular}{lll}
\hline Group & WS $(N=20)$ & CA $(N=19)$ \\
& $M(\mathrm{SD})$ & $M(\mathrm{SD})$ \\
\hline Age (mean, SD) & $8.60(1.62)$ & $8.35(1.75)$ \\
FSIQ & $56.72(10.08)$ & $96.58(2.22)$ \\
Male/female & $10 / 10$ & $10 / 9$ \\
\hline
\end{tabular}


Table 2

Description of ITPA subtests.

\begin{tabular}{ll}
\hline ITPA subtest & \\
\hline $\begin{array}{l}\text { Auditory reception subtest } \\
\text { Visual reception subtest }\end{array}$ & $\begin{array}{l}\text { Assessment of comprehension of oral stimuli } \\
\text { Extraction of meanings indicated by choosing the picture from a set of pictures that } \\
\text { is most similar to a picture stimuli } \\
\text { Relate spoken concepts meaningfully }\end{array}$ \\
$\begin{array}{l}\text { Auditory association subtest } \\
\text { Visual association subtest }\end{array}$ & $\begin{array}{l}\text { Relate pictures of objects meaningfully by matching } \\
\text { Reproduction of a sequence of previously displayed meaningless pictures from memory }\end{array}$ \\
Visual sequential memory subtest & Repetition of forward digits in the same order that they were given \\
Auditory sequential memory subtest & Extraction of the global configuration of masked objects in a complex context \\
Visual closure subtest & Joining together sounds of a word which are omitted \\
Auditory closure subtest & Production of concepts according to a classification system \\
Verbal expression subtest & Use of gestures to express actions \\
Manual expression subtest & Use of grammatical forms to complete a statement \\
Grammatical closure subtest & Synthesis of words from orally presented fragments \\
Sound blending subtest & a
\end{tabular}

a These subtests were not used in this study.

representative). It can be used to analyse intra-individual and inter-individual differences and is individually administered to children whose ages range from 2 years and 6 months to 10 years and 11 months of age. Each test is preceded by demonstrative items; auditory subtests require analysis of words presented orally while visual subtests require that conceptual analysis be related to pictographic stimuli. The ITPA consists of ten principal subtests (auditory reception, visual reception, auditory association, visual association, visual closure, auditory sequential memory, visual sequential memory, verbal expression, manual expression, and grammatic closure), along with two additional subtests (auditory closure and sound blending). These subtests are described in Table 2.

In the current study, data from 8 subtests (visual association, auditory reception, visual reception, auditory association, visual sequential memory, auditory sequential memory, visual closure and auditory closure) will be presented, specifically because (a) the versions of these subtests are the same for Spanish and Brazilian instruments and (b) these subtests have both auditory and visual modalities within the same cognitive dimension (e.g., the reception dimension has subtests for both visual and auditory reception).

\subsection{Procedure}

After collecting consent forms and data about sociodemographic characteristics, diagnosis, clinical history, and general cognitive functioning level (FSIQ), the Illinois Test of Psycholinguistic Abilities (ITPA) was administered to all participants. Neurocognitive tests were administered and scored according to the native language of each participant.

\subsection{Data analysis}

Descriptive analyses were used to characterise each group of participants. Normality and variance homogeneity were tested using the Kolmogorov-Smirnov and Shapiro-Wilk tests. Two different statistical approaches were used. First, we did a within-group analysis for the WS group, in which we compared scalar scores from ITPA subtests with different modalities of input using a paired sample $t$-test. Second, the three groups were compared using a mixed ANOVA with subtest modality as the within-subjects factor and group as the between-subjects factor. Correlations between FSIQ and ITPA scores were performed. The Scheffe post hoc test was used to compare group effects. Bonferroni corrections were performed, and a $p$ value of $p<.02$ (group comparisons) indicated a significant difference.

\section{Results}

In the first section of the results, the pattern of performance in visual vs. auditory information processing subtests of ITPA was presented for the group of individuals with WS. In the second section, we compared individuals in the WS group with typically developing individuals on the same measures.

\subsection{ITPA performance in WS: comparing auditory vs. visual information processing}

A heterogeneous profile was observed for the WS group when we compared visual and auditory information processing (see Fig. 1). Specifically, we observed better performance on the visual reception $(t(19)=4.09$, $p<.01$; visual reception test: $M=32.70, \mathrm{SD}=7.26$ vs. auditory reception test: $M=25.10, \mathrm{SD}=8.35)$ and visual association $(t(19)=2.69, p<.05$; visual association: $M=26.55, \mathrm{SD}=5.62$ vs. auditory association: $M=23.55, \mathrm{SD}=5.00)$ subtests when compared with performance on the auditory reception and auditory association subtests. However, no differences in performance as a function of input modality were observed for either the sequential memory $(t(19)=.222, p>.05)$ or closure $(t(19)=-.116$, $p>.05)$ subtests. 


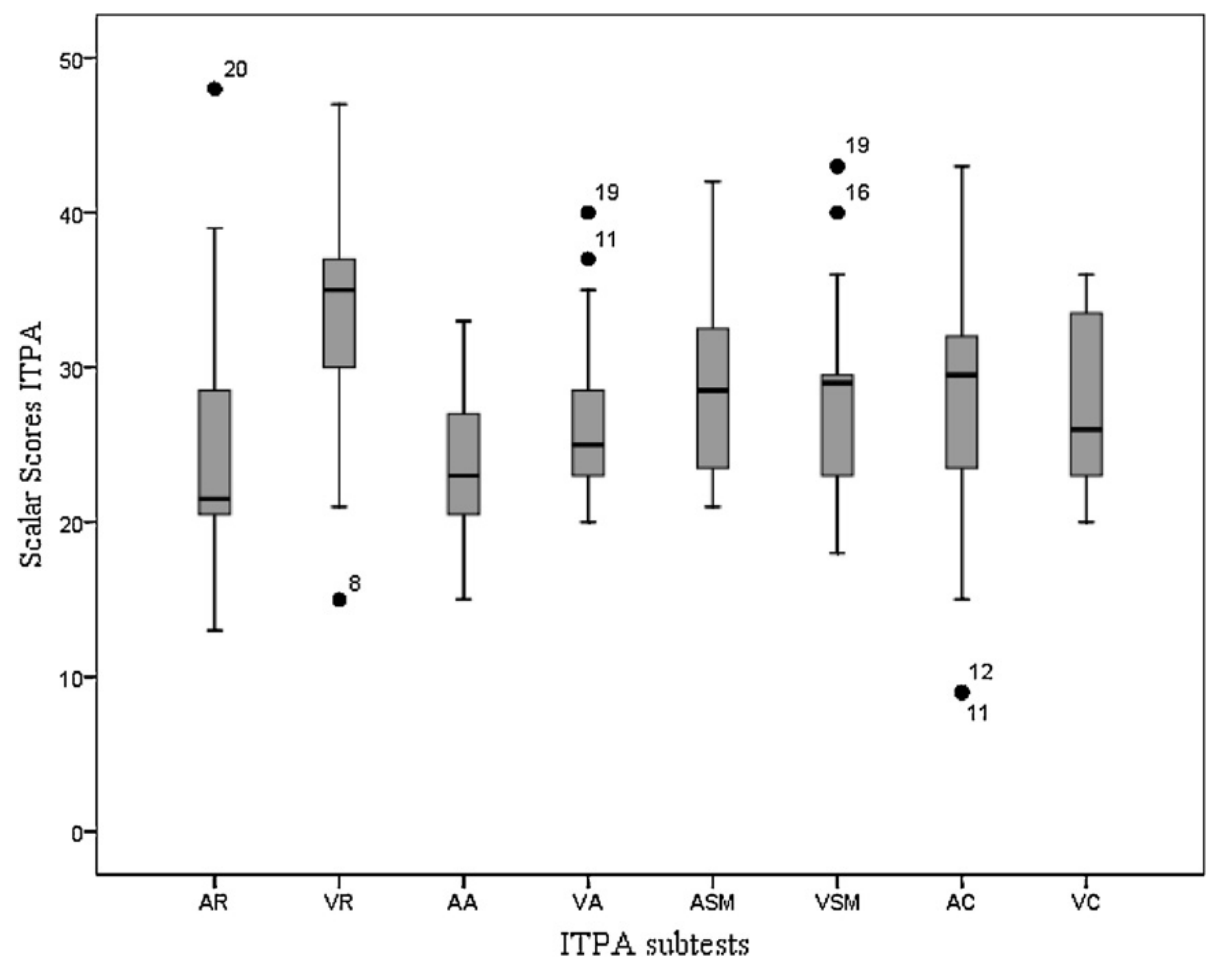

Fig. 1. WS performance on ITPA subtests. Legend: AR - auditory reception subtest; VR - visual reception subtest; AA - auditory association subtest; AV visual association subtest; AMS - auditory sequential memory subtest; VSM - visual sequential memory subtest; AC - auditory closure subtest; VC - visual closure subtest.

\subsection{ITPA performance in WS and typically developing groups: comparing auditory vs. visual information processing}

Group differences regarding ITPA performance on the different subtests, interaction between group and subtests, and group effects (see Table 3 ) were analysed. Effects of subtest were found for reception (auditory and visual) $(F(1,56)=20.59$, $p<.001$ ) and association (visual and auditory) $(F(1,56)=15.72, p<.001$ ). However, no effects of subtest were observed for the sequential memory (visual and auditory) $(F(1,56)=1.54, p>.05)$ and closure (visual and auditory) $(F(1,56)=.54, p>.05)$ subtests. No interaction was found between association and group $(F(2,56)=2.09, p>.05)$, sequential memory and group $(F(2,56)=.92, p>.05)$, or closure and group $(F(1,52)=.04, p>.05)$. Finally, an interaction between performance on reception subtests and group $(F(2,56)=12.30, p<.001)$ was found [visual reception vs. auditory reception: WS $t(19)=-4.09, p<.01$; CA $t(18)=-1.97, p>.05 ; t(19)=-1.19, p>.05)$. The Scheffe post hoc test revealed that the CA and MA groups outperformed the WS group on all ITPA subtests $(p<.02)$. As expected, and because scalar measures were used, we did not observe differences in ITPA performance between the two typically developing groups $(p>.02)$. Finally, no correlations between FSIQ and ITPA scores were found for the three groups $(p>.02)$.

\section{Discussion}

In this study, we used the ITPA to characterise psycholinguistic abilities in a group of children with WS and in two typically developing groups that were matched to the WS group in mental and chronological age. Overall, within-group

Table 3

Performance of WS and typically developing groups in ITPA subtests.

\begin{tabular}{|c|c|c|c|c|}
\hline & $\begin{array}{l}\text { WS }(N=20) \\
M(\mathrm{SD})\end{array}$ & $\begin{array}{l}\mathrm{CA}(N=19) \\
M(\mathrm{SD})\end{array}$ & $\begin{array}{l}\mathrm{MA}(N=20) \\
M(\mathrm{SD})\end{array}$ & $F(2,56)$ \\
\hline Auditory reception & $25.10(8.35)$ & $37.58(1.58)$ & $38.00(1.41)$ & $34.55^{* * * *}$ \\
\hline Visual reception & $32.70(7.26)$ & $38.58(2.29)$ & $38.40(1.60)$ & \\
\hline Auditory association & $23.55(5.00)$ & $36.68(1.46)$ & $36.65(1.53)$ & $108.56^{* * *}$ \\
\hline Visual association & $26.55(5.62)$ & $37.53(2.95)$ & $38.10(1.21)$ & \\
\hline Auditory sequential memory & $28.50(5.59)$ & $36.31(1.72)$ & $36.80(.95)$ & $42.73^{* * *}$ \\
\hline Visual sequential memory & $28.25(6.67)$ & $37.32(1.53)$ & $37.50(.95)$ & \\
\hline Auditory closure & $27.50(8.84)$ & $38.26(1.91)$ & $37.30(.98)$ & $89.39^{* * * *}$ \\
\hline Visual closure & $27.80(5.85)$ & $39.11(1.91)$ & $38.15(1.05)$ & \\
\hline
\end{tabular}

$p<.001$. 
analyses showed that individuals with WS displayed higher scalar scores on the visual reception and visual association subtests in comparison to the auditory reception and auditory association subtests. When the groups were compared, we observed that the WS group demonstrated inferior performance on all ITPA subtests compared with typically developing groups. Moreover, an interaction between reception and group was found; superior performance on the visual reception subtest in comparison to the auditory reception subtest was observed within the WS group.

Our results show superior performance in visual information processing tasks (visual reception and visual association) in WS, which are inconsistent with the data provided by Crisco et al. These differences may be due to different comparison samples. In the Crisco study, a clinically diagnosed WS group was compared with a nonspecific developmental difficulties group, while in our study the WS group was compared with typically developing individuals, matched both on MA and CA. Other case studies using the ITPA showed results that are consistent with the current study (Gejão et al., 2007; Nakamura et al., 1999), which shows that individuals with WS score below normal range on this specific test; that is, the WS group has lower scalar scores than the typically developing groups.

A pattern of strengths and weaknesses within visual processing domains, specifically within visual-spatial cognition, has been shown in WS (Atkinson et al., 2003; Farran \& Jarrold, 2005; Farran, Jarrold, \& Gathercole, 2001; Jarrold, Baddeley, \& Phillips, 2007; Porter \& Coltheart, 2005). Our results are consistent with these findings, namely that individuals with WS do not display a pattern of proficiency in auditory processing (auditory reception, association, closure and sequential memory abilities) when compared with similar subtests of visual processing. Indeed, a careful analysis of the specifics of ITPA auditory processing tests reveals that these subtests require additional skills and different complexity levels that are not required by the visual format. Specifically, auditory reception and association require additional verbal short-term memory skills and conceptual skills, respectively, that have been shown to be impaired in WS (Brock, Brown, \& Boucher, 2006; Porter \& Coltheart, 2005; Sampaio, Sousa, Fernandez, Henriques, \& Goncalves, 2008). This is consistent with the fact that because both the auditory and visual sequential memory tests require short-term memory abilities, no differences between modalities were observed. Additionally, language problems in other language developmental disorders, such as specific language impairment (SLI), are also described as being related to low overall auditory performance on the ITPA (Shaheen, Shohdy, Abd Al Raouf, Mohamed El Abd, \& Abd Elhamid, 2011).

Regarding visual subtests, we observed that only sequential memory and visual closure require abilities that are described as being impaired within WS visual-spatial cognition such as visual spatial rotation, coding spatial relations, and judgement (Atkinson et al., 2003; Farran, 2005; Farran \& Jarrold, 2005; Farran et al., 2001; Hoffman, Landau, \& Pagani, 2003; Pani et al., 1999). Indeed, the cognitive processes underlying visual-spatial construction, mental rotation and spatial relations are not examined by ITPA subtests; visual subtests require conceptual analysis of visual stimuli and semantic categorisation in a similar way to the reception and association subtests. Similar patterns of performance were observed in visual and auditory closure in the WS group, suggesting a commensurate ability to integrate visual and auditory information. Additionally, visual and auditory ITPA tasks require attention abilities, described as one of the main behaviour problems occurring in children of theses ages (7-10 years) who have been diagnosed with WS (Gosch, Stading, \& Pankau, 1994; Leyfer, Woodruff-Borden, Klein-Tasman, Fricke, \& Mervis, 2006; Morris, Demsey, Leonard, Dilts, \& Blackburn, 1988).

While hearing loss is a common clinical finding in individuals with the WS phenotype (Johnson, Comeau, \& Clarke, 2001), particularly among adults (Marler, Elfenbein, Ryals, Urban, \& Netzloff, 2005), we were careful to include only individuals who showed no evidence of hearing problems after being assessed with auditory tests. This methodological consideration avoids the possibility that hearing problems could interfere with our results and limit our ability to extend our results to individuals with WS who display auditory problems.

The results of this study have important implications for the development of educational intervention programs. In particular, our results challenge the widespread idea that learning strategies in individuals with WS should be based upon their proficiency in auditory processing of a stimulus (Semel \& Rosner, 2003). Indeed, our finding that WS performance was enhanced when verbal and visual information were presented together clearly suggests that adding visual input modalities to the presentation of stimuli should be considered when planning intervention programs for this clinical group. The ITPA is described as a useful tool in directing efforts at remediation of language and learning disabilities because it provides a profile of the child's particular cognitive strength and weaknesses (Shaheen et al., 2011).

This was a cross-sectional study. Future studies should be focused on using longitudinal studies and large samples to analyse patterns of response to the ITPA in individuals with WS. We also recognise that while the ITPA provides an important contribution to the understanding of auditory and visual information processing in WS, limiting the auditory vs. visual processing analysis to the specific tasks of this instrument, does not allow us to generalise our results to adult samples. Regardless of the criticisms directed towards the ITPA, we think it is an important tool for the investigation of a variety of visual and auditory information processes required for the development of learning and communication abilities in children with language and/or learning disabilities.

\section{Acknowledgements}

This research was supported by the Coordenação de Aperfeiçoamento de Pessoal de Nível Superior/CAPES (Processo: 1551/08-6) e Prope-UNESP-Santander and grant PIC/IC/83290/2007 from the Fundaçãopara a Ciência e Tecnologia. 


\section{References}

Atkinson, J., Braddick, O., Anker, S., Curran, W., Andrew, R., Wattam-Bell, J., et al. (2003). Neurobiological models of visuospatial cognition in children with Williams syndrome: Measures of dorsal-stream and frontal function. Developmental Neuropsychology, 23(1-2), 139-172.

Bellugi, U., Bihrle, A., Jernigan, T., Trauner, D., \& Doherty, S. (1990). Neuropsychological, neurological, and neuroanatomical profile of Williams syndrome. American Journal of Medical Genetics Supplement, 6, 115-125.

Bellugi, U., Lichtenberger, L., Jones, W., Lai, Z., \& St. George, M. (2000). The neurocognitive profile of Williams syndrome: A complex pattern of strengths and weaknesses. Journal of Cognitive Neuroscience, 12(Suppl. 1), 7-29.

Bogossian, M. A., \& Santos, M. J. (1977). Adaptação brasileira - teste Ilinóis de habilidades psicolingüísticas. Florianópolis: Tamasa.

Brock, J. (2007). Language abilities in Williams syndrome: A critical review. Development and Psychopathology, 19(1), 97-127.

Brock, J., Brown, G. D., \& Boucher, J. (2006). Free recall in Williams syndrome: Is there a dissociation between short- and long-term memory? Cortex, 42(3), 366375.

Cherniske, E. M., Carpenter, T. O., Klaiman, C., Young, E., Bregman, J., Insogna, K., et al. (2004). Multisystem study of 20 older adults with Williams syndrome. American Journal of Medical Genetics A, 131(3), 255-264.

Crisco, J. J., Dobbs, J. M., \& Mulhern, R. K. (1988). Cognitive processing of children with Williams syndrome. Developmental Medicine and Child Neurology, 30(5), 650-656.

Davis, H., \& Silverman, S. R. (1970). Auditory test hearing aids. In H. Davis \& S. R. Silverman (Eds.), Hearing and deafness. Holt: Rinehart and Winston.

Ewart, A. K., Morris, C. A., Atkinson, D., Jin, W., Sternes, K., Spallone, P., et al. (1993). Hemizygosity at the elastin locus in a developmental disorder, Williams syndrome. Nature Genetics, 5(1), 11-16.

Farran, E. K. (2005). Perceptual grouping ability in Williams syndrome: Evidence for deviant patterns of performance. Neuropsychologia, 43(5), 815-822.

Farran, E. K., \& Jarrold, C. (2005). Evidence for unusual spatial location coding in Williams syndrome: An explanation for the local bias in visuo-spatial construction tasks? Brain and Cognition, 59(2), 159-172.

Farran, E. K., Jarrold, C., \& Gathercole, S. E. (2001). Block design performance in the Williams syndrome phenotype: A problem with mental imagery? The Journal of Child Psychology and Psychiatry, 42(6), 719-728.

Gejão, M. G., Silva, J. N. G., Lamônica, D. A. C., De-Vitto, L. P. M., Abramides, D. V. M., \& Richieri-Costa, A. (2007). Evolução de habilidades comunicativas na Síndrome de Williams: Processo terapêutico de um caso clínico. Distúrbios da comunicação, 19(2), 203-211.

Gonçalves, O. F., Pérez, A., Henriques, M., Prieto, M., Lima, M., Siebert, M., et al. (2004). Funcionamento Cognitivo e Produção Narrativa no Síndrome de Williams: Congruência ou Dissociação Neurocognitiva? International Journal of Clinical and Health Psychology, 4, 623-638.

Gosch, A., Stading, G., \& Pankau, R. (1994). Linguistic abilities in children with Williams-Beuren syndrome. American Journal of Medical Genetics, 52(3), 291-296.

Greer, M. K., Brown, F. R., 3rd, Pai, G. S., Choudry, S. H., \& Klein, A. J. (1997). Cognitive, adaptive, and behavioral characteristics of Williams syndrome. American Journal of Medical Genetics, 74(5), 521-525.

Hoffman, J. E., Landau, B., \& Pagani, B. (2003). Spatial breakdown in spatial construction: Evidence from eye fixations in children with Williams syndrome. Cognitive Psychology, 46(3), 260-301.

Jarrold, C., Baddeley, A. D., \& Hewes, A. K. (1998). Verbal and nonverbal abilities in the Williams syndrome phenotype: Evidence for diverging developmental trajectories. The Journal of Child Psychology and Psychiatry, 39(4), 511-523.

Jarrold, C., Baddeley, A. D., \& Phillips, C. (2007). Long-term memory for verbal and visual information in Down syndrome and Williams syndrome: Performance on the doors and people test. Cortex, 43(2), 233-247.

Jarrold, C., Hartley, S. J., Phillips, C., \& Baddeley, A. D. (2000). Word fluency in Williams syndrome: Evidence for unusual semantic organisation? Cognitive Neuropsychiatry, 5(4), 293-319.

Johnson, L. B., Comeau, M., \& Clarke, K. D. (2001). Hyperacusis in Williams syndrome. Journal of Otolaryngology, 30(2), 90-92.

Karmiloff-Smith, A., Brown, J. H., Grice, S., \& Paterson, S. (2003). Dethroning the myth: Cognitive dissociations and innate modularity in Williams syndrome. Developmental Neuropsychology, 23(1-2), 227-242.

Kirk, S., McCarthy, J. J., \& Kirk, W. D. (1986). Test Illinois de Aptitudes Psicolingüisticas. Madrid.

Kirk, S. A., \& McCarthy, J. J. (1961). The Illinois test of psycholinguistic abilities - An approach to differential diagnosis. American Journal of Mental Deficiency, 66, 399-412.

Leyfer, O. T., Woodruff-Borden, J., Klein-Tasman, B. P., Fricke, J. S., \& Mervis, C. B. (2006). Prevalence of psychiatric disorders in 4 to 16 -year-olds with Williams syndrome. American Journal of Medical Genetics B Neuropsychiatry Genetics, 141B(6), 615-622.

Marler, J. A., Elfenbein, J. L., Ryals, B. M., Urban, Z., \& Netzloff, M. L. (2005). Sensorineural hearing loss in children and adults with Williams syndrome. American Journal of Medical Genetics A, 138(4), 318-327.

Martens, M., Wilson, S., \& Reutens, D. (2008). Research Review: Williams syndrome: A critical review of the cognitive, behavioral, and neuroanatomical phenotype. Journal of Child Psychology and Psychiatry, 49(6), 576-608.

Mervis, C. B., Robinson, B. F., Bertrand, J., Morris, C. A., Klein-Tasman, B. P., \& Armstrong, S. C. (2000). The Williams syndrome cognitive profile. Brain and Cognition, 44(3), 604-628.

Morris, C. A., Demsey, S. A., Leonard, C. O., Dilts, C., \& Blackburn, B. L. (1988). Natural history of Williams syndrome: Physical characteristics. Journal of Pediatrics, $113(2), 318-326$

Nakamura, M., Hara, K., Watamaki, T., Nishimura, B., Kumagai, T., Matsumoto, A., et al. (1999). Difficulty in writing Japanese semantic characters in a 9-year-old boy with Williams syndrome. Journal of Intellectual Disabilities Research, 43(Pt 6), 562-567.

Pani, J. R., Mervis, C. B., \& Robinson, B. F. (1999). Global spatial organization by individuals with Williams syndrome. Psychological Science, $10,453-458$.

Porter, M. A., \& Coltheart, M. (2005). Cognitive heterogeneity in Williams syndrome. Developmental Neuropsychology, 27(2), 275-306.

Sampaio, A., Fernandez, M., Henriques, M., Carracedo, A., Sousa, N., \& Goncalves, O. F. (2009). Cognitive functioning in Williams syndrome: A study in Portuguese and Spanish patients. European Journal of Paediatric Neurology, 13(4), 337-342.

Sampaio, A., Sousa, N., Fernandez, M., Henriques, M., \& Goncalves, O. F. (2008). Memory abilities in Williams syndrome: Dissociation or developmental delay hypothesis? Brain and Cognition, 66(3), 290-297.

Schubert, C. (2009). The genomic basis of the Williams-Beuren syndrome. Cellular and Molecular Life Sciences, 66(7), 1178-1197.

Semel, E., \& Rosner, S. R. (2003). Understanding Williams syndrome: Behavioural patterns and interventions. Mahwah: NJ Lawrence Erlbaum Associates.

Shaheen, E. A., Shohdy, S. S., Abd Al Raouf, M., Mohamed El Abd, S., \& Abd Elhamid, A. (2011). Relation between language, audio-vocal psycholinguistic abilities and P300 in children having specific language impairment. International Journal of Pediatric Otorhinolaryngology, 75, 1117-1122.

Stojanovik, V., Perkins, M., \& Howard, S. (2006). Linguistic heterogeneity in Williams syndrome. Clinical Linguistics and Phonetics, $20(7-8)$, 547-552.

Terman, L. M. (1916). The measurement of intelligence: An explanation of and a complete guide for the use of the Stanford revision and extension of the Binet-Simon intelligence scale. Boston: Houghton Mifflin Co.

Wechsler, D. (1989). Wechsler preschool and primary scale of intelligence - Revised. San Antonio, TX: The Psychological Corporation.

Wechsler, D. (1991). Wechsler intelligence scale for children. Manual (3rd ed.). San Antonio: The Psychological Corporation. 